\title{
Avaliação diagnóstica das infecções por vírus Epstein-Barr, parvovírus B19 e vírus linfotrópico de células T humanas em pacientes portadores de lúpus eritematoso sistêmico em hospital de referência do Estado do Pará, Brasil
}

\author{
Diagnostic evaluation of infections by Epstein-Barr virus, parvovirus B19, and human \\ T-cell lymphotropic virus in patients with systemic lupus erythematosus from a \\ reference hospital in Pará State, Brazil
}

\begin{abstract}
Igor Brasil-Costa', Mayara Jane Miranda da Silva ${ }^{1}$, Darleise de Souza Oliveira' , Felipe Bonfim Freitas ', Iran Barros Costa ${ }^{1}$, Larissa Teixeira Meireles' ${ }^{1}$ Bruna Ramos dos Santos ${ }^{1}$, Andreza Paloma Góes Oliveira ${ }^{1}$, Juliana Marinho Melo' , Francinilza Magno Silva', Kelly Beatriz Romeiro Araújo', Alessandra Alves Polaro', Antônio de Moura', Olinda Macedo', Talita Antônia Furtado Monteiro', Manoel Gomes da Silva Filho², Wellington Teixeira Viana Júnior ${ }^{3}$, Carolina Barros Kahwage ${ }^{3}$

Instituto Evandro Chagas/SVS/MS, Seção de Virologia, Ananindeua, Pará, Brasil

2 Instituto Evandro Chagas/SVS/MS, Seção de Patologia, Ananindeua, Pará, Brasi

${ }^{3}$ Hospital Jean Bitar, Departamento de Clínica Médica, Belém, Pará, Brasil
\end{abstract}

\begin{abstract}
RESUMO
lúpus eritematoso sistêmico (LES) é uma doença autoimune crônica, cujo desenvolvimento pode estar associado à infecção por vírus, como o vírus Epstein-Barr (EBV), parvovírus B19 e vírus linfotrópico de células T humanas (HTLV). Durante o período de junho a setembro de 2014, foi realizado um estudo transversal, incluindo 85 pacientes oriundos do Hospital Jean Bitar, na Cidade de Belém, Estado do Pará, Brasil. Foi realizada a pesquisa de anticorpos específicos contra os agentes virais estudados, assim como pesquisa da presença do genoma para EBV e HTLV. Foram avaliadas também variáveis clínicas e epidemiológicas. A maioria dos pacientes eram mulheres, tinham média de idade de 30 anos e se declararam brancos. Para EBV, detectou-se positividade de 37,6\% para lgM, $98,8 \%$ para lgG e 2,4\% por qPCR, com quantificações de 85.028 e 298 cópias do genoma/mL de plasma. Para B19, a positividade para lgM foi 0\% e para lgG 67,1\%. Não houve detecção sorológica ou por qPCR de HTLV. Foi verificada relação estatisticamente significante entre a positividade para lgM anti-EBV e pacientes mais jovens. Esse achado pode estar relacionado com a maior eficiência na produção dessa imunoglobulina nas infecções primárias agudas, que ocorrem geralmente em indivíduos infantes ou adultos jovens. Adicionalmente, o resultado de lgG anti-B19 foi associado à idade avançada dos pacientes, provavelmente por um maior tempo de exposição ao vírus aliado à persistência desse marcador após o contato. A presença dos marcadores não esteve associada às variáveis clínicas e epidemiológicas. Entretanto, o percentual de positividade para o marcador de infecção aguda por EBV pode sugerir um envolvimento do vírus com o LES.
\end{abstract}

Palavras-chave: Lúpus Eritematoso Sistêmico; Vírus Epstein-Barr; Parvovírus B19; HTLV.

\begin{abstract}
Systemic lupus erythematosus (SLE) is a chronic autoimmune disease whose development may be associated with viral infections, such as Epstein-Barr virus (EBV), parvovirus B19, and human T-cell lymphotropic virus (HTLV). A cross-sectional study was performed between June and September 2014 involving 85 patients from the Hospital Jean Bitar, located in Belém, Pará State, Brazil. A survey of specific antibodies against the studied viral agents was conducted, in addition to a survey of the EBV and HTLV genomes. Clinical and epidemiologic variables were also evaluated. Most patients were female, approximately 30 years old, and declared themselves as Caucasians. The following positive results were detected for $\mathrm{EBV}$ : $\lg M=37.6 \%, \lg G=98.8 \%$, and $\mathrm{qPCR}=2.4 \%$, with 85,028 and 298 copies of the genome per milliliter of plasma. Positive results for B19 were: $\lg M=0 \%, \lg G=67.1 \%$. Serological or qPCR detection did not reveal HTLV. A significant statistical correlation was observed between anti-EBV $\lg M$ antibodies and younger patients. These findings may be related to the highly efficient production of this immunoglobulin during acute primary infections, which frequently occurs in children and young adults. Furthermore, the results for anti-B19 IgG were associated with the patients' advanced age, resulting from the longer exposure period to the virus combined with this marker's persistence after exposure. Presence of the marker was not associated with clinical and epidemiological variables. However, the percentage of cases of acute infection by the EBV marker suggests an association with SLE.
\end{abstract}

Keywords: Systemic Lupus Erythematosus; Epstein-Barr Virus; Parvovirus B19; HTLV.

Correspondência / Correspondence:

Igor Brasil-Costa

Instituto Evandro Chagas, Seção de Virologia, Laboratório de Vírus Epstein-Barr

Rodovia BR-316 km 7, s/n. Bairro: Levilândia - CEP: 67030-000 - Ananindeua, Pará, Brasil - Tel.: + 55 (91) $3214-2005$

E-mail: igorcosta@iec.pa.gov.br 


\section{INTRODUÇÃO}

O lúpus eritematoso sistêmico (LES) é uma doença autoimune crônica que pode apresentar variadas manifestações clínicas entre os pacientes afetados e é caracterizada por períodos de atividade e remissão da doença ${ }^{1,2,3}$. $O$ LES pode surgir em indivíduos de qualquer faixa etária, entretanto, ocorre em 90\% dos casos em mulheres entre a segunda e a terceira década de vida ${ }^{4}$.

A etiologia e patogênese do LES ainda não estão completamente esclarecidas, porém vários fatores são associados ao aumento da suscetibilidade à doença. Dentre os principais estão a predisposição genética, a exposição à luz ultravioleta, o uso de medicamentos, os defeitos hormonais e as infecções virais $5,6,7,8,9$. $\bigcirc$ diagnóstico da doença pode ser feito pela avaliação da presença de pelo menos quatro de 11 critérios estabelecidos pelo American College of Rheumatology 10,11

Devido à ausência de terapias de cura ou tratamento específico, os pacientes diagnosticados com LES são submetidos a um manejo clínico que objetiva o controle da atividade da doença pela administração de drogas imunossupressoras ou antimetabólitos, como predinizona, azatioprina e metotrexato. $\bigcirc$ grau de atividade da doença é avaliado pelo critério SLEDAI (Systemic Lupus Erythematosus Disease Activity Index), que também analisa a efetividade do tratamento 3,12 .

Entre os agentes infecciosos mais envolvidos com a patogênese do LES, os mais importantes são o vírus Epstein-Barr (EBV), o parvovírus B19 (B19), o vírus linfotrópico de células $T$ humanas (HTLV) e o citomegalovírus humano (HCMV) 9,13. Essas infecções virais podem contribuir para 0 surgimento da doença pela produção de proteínas virais com estruturas similares a algumas proteínas humanas $^{8}$, podendo gerar autoanticorpos pela reação cruzada de anticorpos produzidos contra os vírus ou modificação no processamento dos antígenos 9,14 e desequilíbrio na regulação de linfócitos $T$ e $B$ e na apoptose $^{15}$.

EBV pertence à ordem Herpesvirales, família Herpesviridae, subfamília Gammaherpesvirinae, gênero Lymphocryptovirus e hoje denomina-se Human gammaherpesvirus 4 (espécie) $^{16}$. $\bigcirc$ vírus apresenta genoma de DNA de fita dupla (DNAfd) linear, composto por cerca de 87 genes codificantes ${ }^{17}$ e envolvido por um capsídeo icosaédrico com 162 capsômeros, tegumento e envelope composto por glicoproteínas ${ }^{18}$. $\bigcirc$ vírus é altamente disseminado, infectando cerca de $90 \%$ da população mundial ${ }^{19}$.

A infecção por EBV tem sido associada ao LES, tanto no surgimento quanto na atividade da doença, por meio de estudos sorológicos e de detecção direta do genoma viral ${ }^{20,21,22}$. $\bigcirc$ mecanismo pelo qual o vírus interfere no surgimento e na atividade da doença pode ser explicado pelo mimetismo molecular da proteína viral EBNA1 com alguns autoantígenos ${ }^{21,23,24}$.
B19 pertence à família Parvoviridae, subfamília Parvovirinae, gênero Erythroparvovirus e hoje denomina-se Primate erythroparvovirus 1 (espécie) ${ }^{16}$. Ele é um pequeno vírus de DNA de fita simples (DNAfs), não envelopado, com simetria icosaédrica, medindo entre 22 e $24 \mathrm{~nm}^{25}$. A prevalência mundial varia de 15 a $90 \%$ conforme a faixa etária $26,27,28,29,30$.

A infecção pelo B19 ocasiona, principalmente, manifestações que se assemelham às das doenças reumáticas autoimunes, como exantemas, citopenias e artrites, além de induzir a produção transitória de autoanticorpos e citocinas pró-inflamatórias ${ }^{31}$. mecanismo para a associação do B19 com LES pode ser resultante da secreção de autoanticorpos anti-DNAfs hidrolizantes, resultantes da resposta ao DNAfs viral replicante. Esse processo causaria a morte celular, expondo o sistema imune a um novo conjunto de antígenos e assim manteria a doença ativa ${ }^{32}$. Outros mecanismos propostos para a ação do B19 incluem a citotoxicidade da proteína NS1, levando à apoptose $^{33}$, reação cruzada do anticorpo anti-B19 lgG com autoantígenos humanos ${ }^{34}$ e produção de citocinas pró-inflamatórias $27,35,36,37$.

O HTLV pertence à família Retroviridae, subfamília Orthoretrovirinae, gênero Deltaretrovirus e hoje denomina-se Primate T-lymphotropic virus (espécie) ${ }^{16}$. Trata-se de um vírus envelopado, com genoma constituído por RNA de fita simples (RNAfs) diploide, envolvido por um capsídeo. Existem quatro tipos de HTLV, dos quais o tipo 1 é o mais prevalente. Estima-se que 20 milhões de pessoas no mundo estejam infectadas pelo HTLV-1, das quais aproximadamente 90\% permanecerão assintomáticas ao longo da vida ${ }^{38}$.

A infecção pelo HTLV gera mudanças na resposta imune sistêmica, alterando 0 equilíbrio entre os perfis Th1 e Th2. $\bigcirc$ vírus altera a atividade regulatória de células $\mathrm{T} \mathrm{CD}^{+}{ }^{+}$, consequentemente afetando a homeostasia entre diversas citocinas como IFN- $\gamma$, TNF- $\alpha$, TGF- $\beta$ e IL-10, o que ocasiona - desbalanceamento entre respostas inflamatórias e anti-inflamatórias, ocasionando a perda da tolerância e o desenvolvimento da autoimunidade ${ }^{39}$. Estudos desenvolvidos em camundongos transgênicos que carregavam genes específicos dos retrovírus, como - gene tax, mostravam patologias semelhantes à autoimunidade, sugerindo que 0 vírus tivesse 0 potencial de induzir desordens autoimunes ${ }^{40,41}$.

Diante da influência deletéria desses vírus no equilíbrio do sistema imunológico e devido ao desequilíbrio desse sistema ser a causa final das doenças autoimunes, torna-se extremamente relevante - estudo dos agentes em pacientes acometidos pelo LES.

\section{MATERIAIS E MÉTODOS}

\section{POPULAÇÃO DE ESTUDO E COLETA DAS AMOSTRAS}

No período de junho a setembro de 2014, foi realizado um estudo transversal, incluindo 85 pacientes diagnosticados com LES, de acordo com os critérios do American College of Rheumatology, 
atendidos no Hospital Jean Bitar, centro de referência no tratamento da doença no Estado do Pará. As informações laboratoriais, clínicas e demográficas foram obtidas por meio de um questionário ou pela consulta aos prontuários médicos. A atividade da doença foi determinada pelo SLEDAI, no qual pacientes com doença ativa apresentam um score superior a 4. $\bigcirc$ SLEDAl foi mensurado pela avaliação conjunta dos seguintes sinais ou sintomas: febre, leucopenia, plaquetopenia, rash malar, úlcera oral, alopecia, pleurite, positividade para anticorpo anti-DNA, artrite, miosite, hematúria, leucocitúria, proteinúria, presença de cilindros no exame de sedimentação da urina, vasculite, cefaleia, níveis deprimidos de componentes do sistema complemento, neuropatias cranianas, síndrome orgânica cerebral e acidente vascular cerebral.

estudo foi aprovado pelo Comitê de Ética em Pesquisa do Instituto Evandro Chagas (IEC) na Plataforma Brasil, com CAAE $n^{\circ}$ 30366114.0.0000.0019, com parecer número 672.317, em 21 de maio de 2014. Todos os pacientes, antes de serem incluídos na pesquisa, assinaram um Termo de Consentimento Livre e Esclarecido e responderam a um questionário epidemiológico.

De cada paciente, foram coletados $5 \mathrm{~mL}$ de sangue total em tubos contendo EDTA K2 como anticoagulante. Após a coleta, todas as amostras foram conduzidas ao IEC, submetidas ao teste de hemograma e, em seguida, à centrifugação por $10 \mathrm{~min}$, a $1.400 \mathrm{~g}$ (3.000 rpm) para a separação do plasma e porção celular (buffy coat). Posteriormente, as amostras foram armazenadas a $-70^{\circ} \mathrm{C}$ até o momento do uso.

\section{TESTES SOROLÓGICOS}

O plasma foi utilizado para a pesquisa de anticorpos específicos contra os agentes virais estudados (EBV, B19 e HTLV). Foi utilizada a metodologia de ELISA com auxílio dos kits RIDASCREEN ${ }^{\circledR} \quad$ EBV/NCA IgM (R-Biopharm), RIDASCREEN $^{\circledR}$ EBV/VCA lgG (R-Biopharm), Parvovirus B IgM Enzyme Immunoassay (Biotrin), Parvovirus IgG Enzyme Immunoassay (Biotrin) e Gold ELISA HTLV-I/II (REM). Todos os testes foram realizados seguindo os protocolos descritos pelos fabricantes.

\section{EXTRAÇÃO DO DNA VIRAL E REAÇÃO EM CADEIA DA POLIMERASE QUANTITATIVA}

Foi realizada extração de DNA a partir do plasma e do buffy coat, por meio do kit QIAamp DNA Mini (Qiagen), de acordo com o protocolo recomendado pelo fabricante. Para as amostras de plasma, foram adicionados $10 \mu \mathrm{L}$ do controle exógeno comercial CPE (Nanogen), o qual possui sequências sintéticas do gene da $\beta$-globina humana.

- teste de detecção qualitativa e quantitativa de EBV foi realizado a partir do DNA extraído do plasma, utilizando a metodologia de reação em cadeia da polimerase quantitativa (qPCR), por meio do kit comercial EBV Alert (Nanogen), de acordo com o protocolo do fabricante. $\bigcirc$ kit teve como alvos os genes EBNA1 de EBV (marcador FAM) e da $\beta$-globina humana (marcador $\mathrm{VIC}$ ), além de contar com quatro amostras com concentrações conhecidas $\left(10^{5}, 10^{4}, 10^{3}\right.$ e 102) de DNA do EBV para confecção de uma curva padrão para quantificação.

A pesquisa do proviral DNA do HTLV-1/2 foi realizada por qPCR a partir do DNA extraído do buffy coat. Foram utilizadas três sequências alvo: as regiões não homólogas do gene pol do HTLV-1 e HTLV-2, e o gene da albumina como controle endógeno da reação. As sequências dos primers e sondas contidos nos ensaios, assim como o protocolo utilizado, foram descritos segundo Tamegão-Lopes et $\mathrm{al}^{42}$.

Todas as reações foram executadas no equipamento Rotor-Gene Q (Qiagen) e as análises de amplificação foram feitas no software do equipamento.

\section{ANÁLISE ESTATÍSTICA}

Foi realizada estatística descritiva para as variáveis clínicas e epidemiológicas da população estudada. $\bigcirc$ teste de Qui-quadrado e o teste $G$ foram utilizados para testar associação de variáveis categóricas com os desfechos de positividade para os vírus estudados e seus marcadores. O teste de Kruskal-Wallis foi escolhido para avaliar a associação da idade dos pacientes com os desfechos de positividade para os vírus estudados e seus marcadores. Todos os testes foram conduzidos com o auxílio do pacote estatístico BioEstat v5.043. A significância estatística foi definida quando o valor de p apresentou-se inferior a 0,05.

\section{RESULTADOS}

\section{AVALIAÇÃO CLÍNICA E EPIDEMIOLÓGICA}

Dos 85 participantes do estudo, 91,8\% eram do sexo feminino e $8,2 \%$ do masculino. Quanto à distribuição por faixa etária, a idade dos pacientes variou de 14 a 69 anos, com média de 30 anos. Dentre as opções de etnia indagadas, 36,4\% (31/85) dos pacientes declarou-se branca, 30,6\% (26/85) negra e 16,5\% (14/85) parda. Para a análise de etnia, houve ausência da informação para 14 pacientes (16,5\%). Para a avaliação do índice SLEDAI, observou-se que 83,5\% (71/85) dos pacientes possuíam a ficha médica de determinação do índice preenchida. $O$ SLEDAl variou de 0 a 24 entre os 71 pacientes, com média de 6,9. As principais manifestações clínicas encontradas nesses pacientes foram: proteinúria $(24 / 71$; 33,8\%), cefaleia $(20 / 71$; $28,2 \%)$, alopecia $(18 / 71 ; 25,4 \%)$, hematúria (16/71; $22,5 \%)$, leucopenia $(9 / 71 ; 12,7 \%)$ e febre $(8 / 71$; $11,3 \%)$.

\section{EBV}

Pela avaliação sorológica, 37,6\% (32/85) dos pacientes apresentaram resultado positivo para $\operatorname{lgM}$ contra EBV. Quanto à detecção de anticorpos lgG, $98,8 \%$ (84/85) mostraram-se positivos e em 1,2\% (1/85) o teste foi inconclusivo. 
A positividade para $\lg M$ mostrou-se associada a pacientes mais jovens pelos testes de Qui-quadrado ( $p=0,0127)$ e Kruskal-Wallis $(p=0,0090)$. As demais variáveis epidemiológicas não apresentaram relação estatística $(p>0,05)$ (Tabela 1 e Figura 1). Em relação à atividade da doença medida pelo SLEDAI, 46,4\% $(13 / 28)$ dos pacientes positivos estavam com doença ativa, entretanto, não houve significância estatística para a associação pelo teste de Qui-quadrado ( $p=0,3336)$.

Dentre os sinais e sintomas mais apresentados por pacientes soropositivos lgM anti-EBV estão: leucopenia
$(8 / 28-28,6 \%)$, proteinúria $(7 / 28-25 \%)$, cefaleia $(6 / 28-21,4 \%)$, hematúria $(5 / 28-17,8 \%)$ e rash malar (5/28 - 17,8\%). Nenhum sinal ou sintoma apresentou-se individualmente relacionado à positividade para $\lg M$ anti-EBV ( $>>0,05)$.

Pela metodologia de qPCR, observou-se que duas amostras $(2,4 \%)$ de plasma apresentavam material genômico de EBV, com quantificação de 85.028 e 298 cópias do genoma viral/mL de plasma. Não houve relação alicerçada estatisticamente $(p>0,05)$ entre a positividade ou quantificação para EBV e os dados sorológicos, epidemiológicos ou clínicos.

Tabela 1 - Relação das variáveis clínicas e epidemiológicas para pacientes portadores de LES com a positividade para ELISA IgM anti EBV

\begin{tabular}{|c|c|c|c|c|}
\hline \multicolumn{2}{|c|}{ Variável } & \multicolumn{2}{|c|}{ ELISA IgM anti-EBV } & \multirow{2}{*}{ Valor de $p$} \\
\hline & & Positivo & Negativo/Inconclusivo & \\
\hline \multirow{2}{*}{ Sexo } & Masculino & 3 & 4 & \multirow{2}{*}{0,7665} \\
\hline & Feminino & 29 & 49 & \\
\hline \multirow{2}{*}{ Idade } & $>30$ anos & 11 & 33 & \multirow{2}{*}{0,0127} \\
\hline & $\leq 30$ anos & 21 & 20 & \\
\hline \multirow{4}{*}{ Etnia } & Branca & 15 & 16 & \multirow{4}{*}{0,1927} \\
\hline & Negra & 7 & 19 & \\
\hline & Parda & 4 & 10 & \\
\hline & Sem informação* & 6 & 8 & \\
\hline \multirow{3}{*}{ SLEDAI } & $>4$ & 13 & 25 & \multirow{3}{*}{0,3336} \\
\hline & $\leq 4$ & 15 & 18 & \\
\hline & Sem informação* & 4 & 10 & \\
\hline
\end{tabular}

* Não considerado nas análises estatísticas.

A

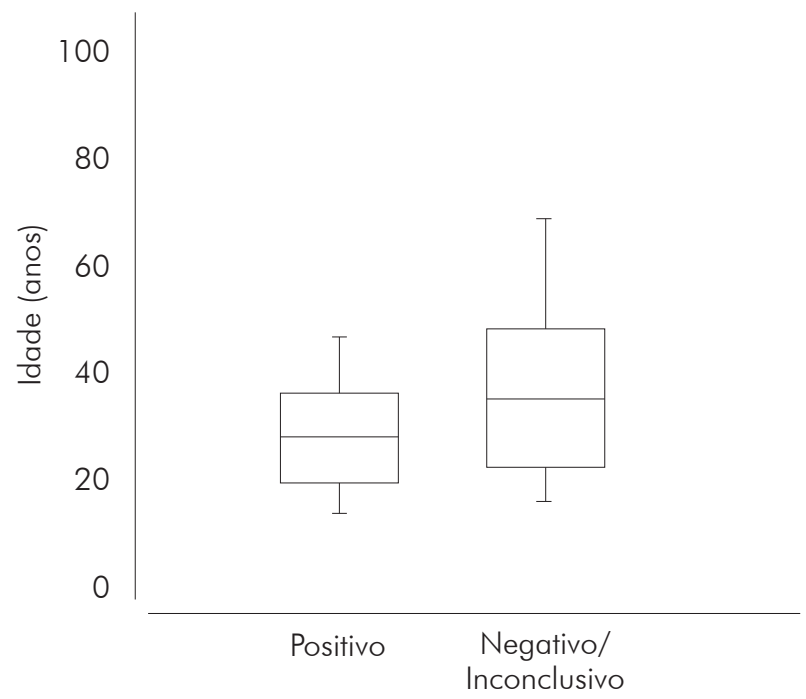

B

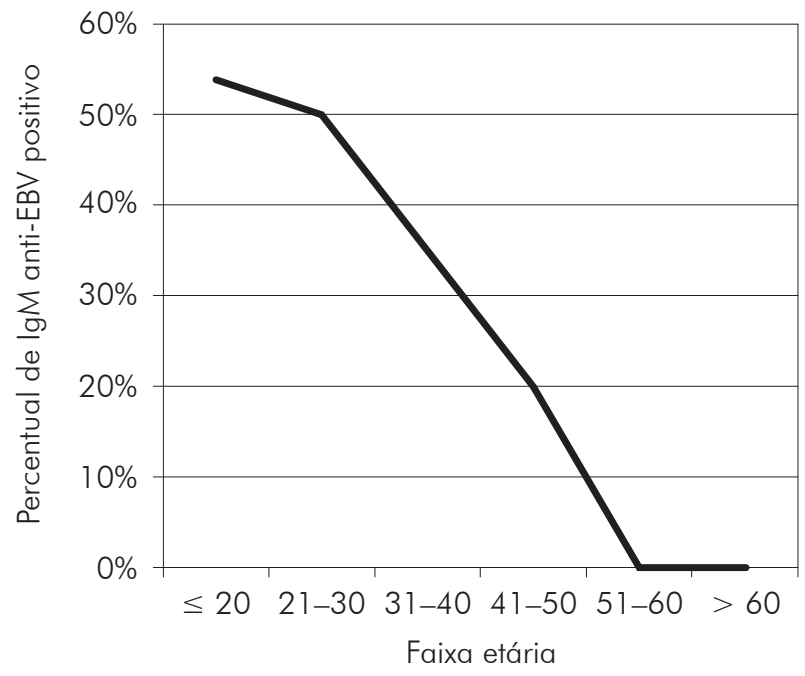

A: Gráfico boxplot da distribuição etária para os pacientes de acordo com a positividade para lgM anti-EBV, considerando um desvio padrão; B: Percentual de positividade para anticorpos lgM contra EBV de acordo com a faixa etária.

Figura 1 - Relação da positividade para lgM anti-EBV com a idade dos pacientes portadores de LES 


\section{B19}

Os resultados dos testes sorológicos revelaram que nenhum dos pacientes apresentava anticorpos de classe lgM contra B19 detectáveis. Em relação aos anticorpos lgG, 67,1\% (57/85) dos pacientes mostraram evidência de ter entrado em contato prévio com esse vírus. A avaliação da associação das variáveis clínicas e epidemiológicas não demonstrou relação estatística pelo teste de Qui-quadrado ( $p>0,05)$ (Tabela 2). Entretanto, a avaliação estatística pelo teste de Kruskal-Wallis demonstrou que os indivíduos com idade mais avançada possuem maior probabilidade de apresentar resultado positivo para $\lg G(p=0,0087)$ (Figura 2).

Dentre os sinais e sintomas mais apresentados por pacientes soropositivos para essa imunoglobulina estão: proteinúria $(19 / 49$ - 38,8\%), cefaleia $(14 / 49$ - 28,6\%), hematúria (11/49 - 22,4\%) e alopecia (9/49 - 18,4\%). Nenhum sinal ou sintoma apresentou-se individualmente relacionado à positividade no teste sorológico $(p>0,05)$.

Tabela 2 - Relação das variáveis clínicas e epidemiológicas para pacientes portadores de LES com a positividade para ELISA $\lg G$ anti-B19

\begin{tabular}{|c|c|c|c|c|}
\hline \multicolumn{2}{|c|}{ Variável } & \multicolumn{2}{|c|}{ ELISA IgG anti-B19 } & \multirow{2}{*}{ Valor de $\mathrm{p}$} \\
\hline & & Positivo & Negativo/Inconclusivo & \\
\hline \multirow{2}{*}{ Sexo } & Masculino & 6 & 1 & \multirow{2}{*}{0,2730} \\
\hline & Feminino & 51 & 27 & \\
\hline \multirow{2}{*}{ Idade } & $>30$ anos & 33 & 11 & \multirow{2}{*}{0,1066} \\
\hline & $\leq 30$ anos & 24 & 17 & \\
\hline \multirow{4}{*}{ Etnia } & Branca & 21 & 10 & \multirow{4}{*}{0,4324} \\
\hline & Negra & 18 & 8 & \\
\hline & Parda & 12 & 2 & \\
\hline & Sem informação* & 6 & 8 & \\
\hline \multirow{3}{*}{ SLEDAI } & $>4$ & 25 & 13 & \multirow{3}{*}{0,5284} \\
\hline & $\leq 4$ & 24 & 9 & \\
\hline & Sem informação* & 8 & 6 & \\
\hline
\end{tabular}

${ }^{*}$ Não considerado nas análises estatísticas.

A

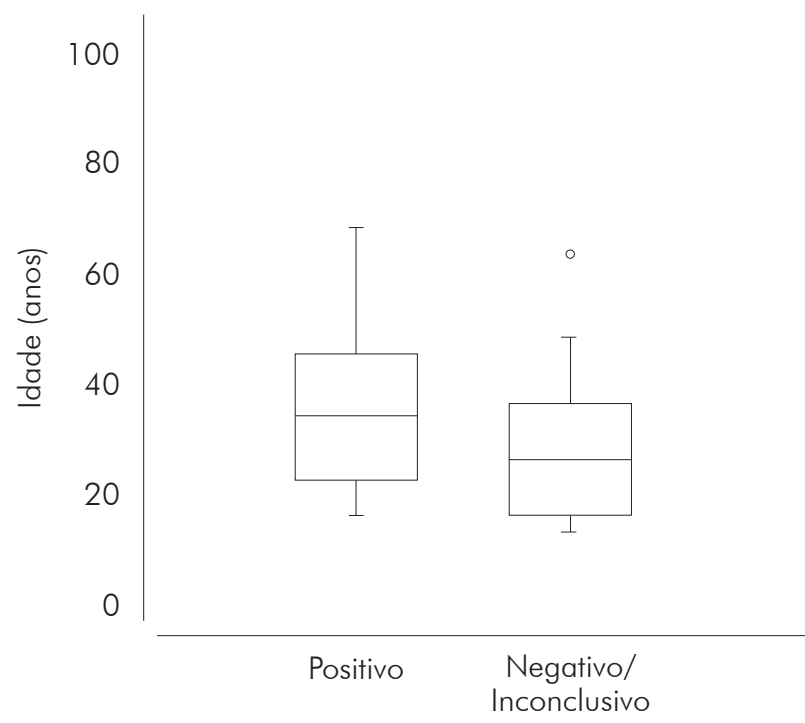

B

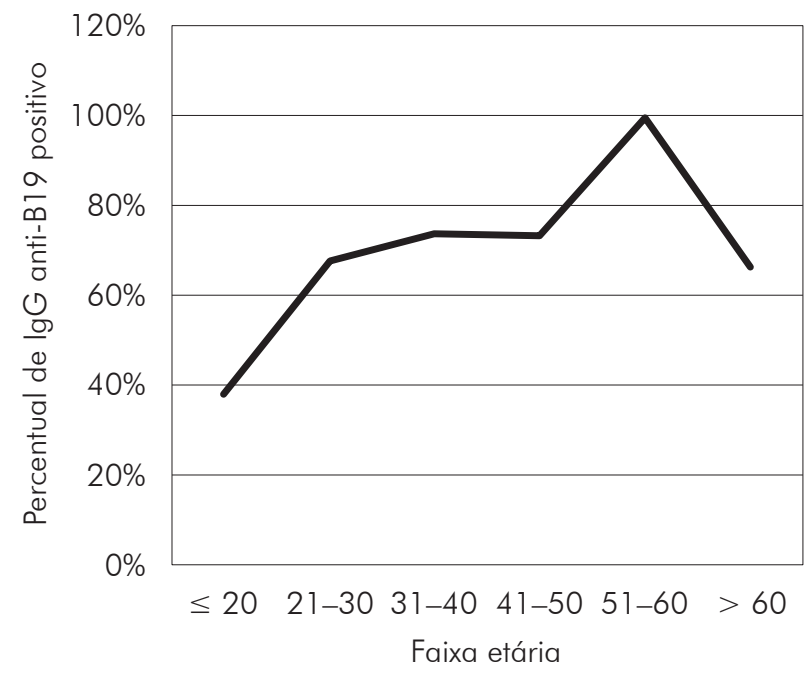

A: Gráfico boxplot da distribuição etária para os pacientes de acordo com a positividade para lgG anti-B19, considerando um desvio padrão; B: Percentual de positividade para anticorpos lgG contra B19 de acordo com a faixa etária.

Figura 2 - Relação da positividade para lgG anti-B19 com a idade dos pacientes portadores de LES 


\section{HTLV}

Todos os 85 pacientes foram negativos para a presença de anticorpos anti-HTLV. A metodologia de qPCR também não detectou a presença do proviral DNA nas amostras extraídas a partir do buffy coat. Os valores obtidos no teste de hemograma, assim como as variáveis clínicas e epidemiológicas, não puderam ser relacionados à infecção devido à ausência de casos positivos.

Adicionalmente, não houve relação entre a positividade dos marcadores sorológicos encontrados para os três vírus entre si $(p>0,05)$, excluindo-se qualquer suspeita de reação cruzada e enfraquecendo a hipótese de coinfecções.

\section{DISCUSSÃO}

Devido à falta de definição para a etiologia e patogênese do LES, a doença tem sido alvo de estudos, visando uma melhor compreensão da presença de fatores de risco e dos mecanismos pelos quais esses fatores interferem no bom funcionamento do sistema imunológico. Entre os principais fatores relacionados, estão as infecções virais por EBV, B19 e HTLV1,2,3.

Entre os pacientes estudados, a grande maioria era representante do sexo feminino, em consonância com o percebido da literatura ${ }^{44}$. A associação de LES com as mulheres ocorre pelo fato de que existe, ainda que por um mecanismo pouco elucidado, uma suscetibilidade maior ao desenvolvimento dessa doença ${ }^{45}$. Experimentalmente, foi comprovado que um segundo cromossomo $X$ aumenta a gravidade do LES ${ }^{46}$. Os hormônios sexuais femininos também possuem papel importante no aumento da suscetibilidade feminina ao desenvolvimento de LES quando comparado com homens ${ }^{47}$.

Os resultados da avaliação étnica ainda são bastante controversos. Sauma et $a^{48}$ descreveram a doença afetando mais indivíduos brancos (53,8\%). Entretanto, em 2009, Conde et al ${ }^{44}$ observaram um padrão contrário, com $60 \%$ dos casos ocorrendo em pacientes não brancos. No presente estudo, houve uma predominância de brancos, entretanto, negros e pardos somados ultrapassaram o percentual de brancos. Além da proximidade nos valores percentuais de cada etnia oriunda de uma população altamente miscigenada, qualquer conclusão fica prejudicada devido à subjetividade inerente a essa variável, além da considerável perda de informações da definição de etnia dos pacientes (16,5\%).

A associação da infecção por EBV e o LES tem sido relatada em vários estudos, mediante evidências sorológicas e moleculares $22,49,50$. Em pacientes com a doença, há uma soroconversão mais rápida para EBV e um valor de carga viral superior quando comparados a indivíduos infectados pelo vírus e sem LES51,52. A associação é reforçada pelo mimetismo da proteína EBNAl de EBV com o antígeno lúpico Ro e pela incapacidade dos linfócitos ${\mathrm{T} \mathrm{CD}^{+}}^{+}$em controlar os linfócitos $B$ infectados pelo vírus ${ }^{21,53}$. Apesar de não ser encontrada diferença estatística entre os marcadores de infecção por EBV e os critérios clínicos da doença, observou-se um percentual considerável de pacientes com positividade para o marcador sorológico de infecção aguda pelo vírus, o que sugere um envolvimento do vírus com o LES.

A associação encontrada entre a positividade para $\lg M$ e pacientes jovens pode ser explicada pelas diferentes eficiências na produção da imunoglobulina de acordo com a fase da infecção. Para infecções primárias agudas, nota-se uma produção de $\lg M$ mais eficiente em relação aos períodos de reativação do EBV ${ }^{54}$. Como as infecções primárias pelo vírus ocorrem, em sua grande maioria, em crianças e adultos jovens ${ }^{18}$, isso explicaria a associação dessa resposta humoral aguda com pacientes menos senis. Outra explicação seria o nível de estresse ao qual o paciente é submetido. Uma vez que adultos jovens economicamente ativos são mais acometidos pelo estresse, eles terão maior suscetibilidade aos eventos de reativação do $E B V^{55}$.

Estudos apontam para um alto percentual de positividade para EBV em pacientes com LES por PCR, variando de $41,9 \%$ até 98,5\%56,57,58,59. No entanto, a maioria utiliza amostras celulares, como sangue total e células mononucleares do sangue periférico. $\bigcirc$ resultado obtido, a partir da detecção do genoma do EBV, foi inferior ao esperado, entretanto, devido ao padrão de infecção ser mais latente, com baixa produção e liberação de novas partículas virais ${ }^{60}$, é possível que a carga viral livre no plasma tenha sido muito baixa no instante da coleta. Outro fator importante que justifica o monitoramento da infecção é a presença do marcador sorológico lgG em 99\% dos pacientes, o que indica que quase a totalidade já entrou em contato com o EBV e pode estar abrigando esse vírus em suas células.

A semelhança entre as características da infecção pelo B19 e o LES tem sugerido um possível papel para esse vírus na patogênese do lúpus, desencadeando a doença ou exarcebando seus sintomas 9,61,62,63,64. Entretanto, não se observou positividade para anticorpos lgM. Por outro lado, observou-se uma positividade de $67,1 \%$ para $\lg G$ anti-B19.

Em Taiwan, Chen et al ${ }^{65}$ também observaram ausência de anticorpos $\operatorname{lgM}$ em pacientes com LES. Anticorpos lgG, por outro lado, foram detectados tanto em pacientes quanto em controles $(46,6 \%$ em LES e 46,9\% nos controles). No Brasil, Silva et al66 encontraram $15,6 \%$ de positividade para $\lg M$ e $84,4 \%$ para lgG em pacientes com a doença. Neste estudo não foi descartada a possibilidade de que a positividade observada seja um reflexo da circulação do vírus na população de Belém, a qual já foi estimada entre $43 \%$ e $85 \%$, entre diferentes segmentos populacionais $^{67,68,69}$, onde os autores denotaram uma circulação endêmica desse agente viral entre indivíduos suscetíveis daquela localidade.

Não houve associação do resultado de $\lg G$ com as variáveis clínicas, o que corrobora outros estudos com 
pacientes com doenças autoimunes ${ }^{66,70}$. Entretanto, a variável idade mostrou-se fortemente associada à positividade para lgG anti-B19. A hipótese que pode sustentar essa associação é de que, com o avanço da idade, haja uma contínua exposição ao vírus e consequente aumento da probabilidade de contato ${ }^{25,71}$. Uma vez em contato, o organismo produz lgG, a qual pode permanecer na circulação por vários anos ${ }^{72}$.

No Brasil, a prevalência da infecção por HTLV-1 é de 0,41\% (0,08-1,35\%), apresentando-se maior em indivíduos com comportamento de risco para adquirir doenças sexualmente transmissíveis, em pacientes politransfundidos e usuários de drogas endovenosas ${ }^{73,74,75}$. No presente estudo, o baixo número amostral poderia influenciar diretamente na detecção, considerando-se a prevalência da infecção na população geral, o que ajudaria a explicar a ausência da soropositividade no grupo avaliado.

Os resultados confirmaram achados de estudos anteriores realizados em áreas endêmicas, utilizando diversos métodos diagnósticos e que não encontraram soropositivos entre pacientes com $\operatorname{LES}^{76,77,78,79}$. A relação do HTLV com o LES ainda permanece obscura. Alguns estudos não encontraram associação ${ }^{80,81}$; entretanto, altos níveis de títulos de anticorpos anti-HTLV-1 podem estimular a resposta imune que leva a danos teciduais inflamatórios. Alguns relatos evidenciaram uma correlação positiva entre o HTLV-1 e algumas manifestações do LES, com prevalências de infecção variando de $11 \%$ a
15\%82,83,84,85,86. Complementarmente, Carvalho et $a^{87}$ relataram que $0,7 \%$ dos indivíduos com HTLV-1 manifestavam LES.

Durante o desenvolvimento da autoimunidade, existe uma combinação de diversos fatores que não são somente imunológicos, mas genéticos e ambientais. Dentre os fatores ambientais, as infecções por agentes infecciosos podem apresentar grande importância, podendo representar o "gatilho" para a autoimunidade, principalmente pelo processo de mimetismo molecular entre diversas proteínas do vírus com estruturas celulares do hospedeiro $21,23,24,34,88$ ou representar uma ação sinérgica para a manifestação dos sintomas relacionados ${ }^{22,63,64}$.

\section{CONCLUSÃO}

Este é um estudo pioneiro na Amazônia brasileira sobre a presença de EBV, B19 e HTLV em pacientes com LES. A idade dos pacientes com LES pode sugerir uma diferença na interpretação dos resultados sorológicos, devido à diferença de eficiência na produção de anticorpos nas fases de infecção aguda primária e reativação ou aos níveis de estresse aos quais os indivíduos são submetidos em cada faixa etária. Sugere-se executar novos estudos na região avaliando os pacientes antes do início do tratamento, com um número amostral mais elevado e um grupo controle correspondente, para obtenção de uma análise mais acurada da associação dos vírus com a doença.

\section{REFERÊNCIAS}

1 Smith CD, Cyr M. The history of lupus erythematosus. From Hippocrates to Osler. Rheum Dis Clin North Am. 1988 Apr;14(1):1-14.

2 Watanabe T, Tsuchida T. Classification of lupus erythematosus based upon cutaneous manifestations. Dermatological, systemic and laboratory findings in 191 patients. Dermatology. 1995; 190(4):277-83

3 Gladman DD, Ibañez D, Urowitz MB. Systemic lupus erythematosus disease activity index 2000. J Rheumatol. 2002 Feb;29(2):288-91.

4 Tan TC, Fang H, Magder LS, Petri MA. Differences between male and female systemic lupus erythematosus in a multiethnic population. J Rheumatol. 2012 Apr;39(4):759-69.

5 Teixeira TM, Costa CL. Papel da vitamina D no lúpus eritematoso sistêmico. Rev Nutr. 2012 jul-ago;25(4):531-8.

6 Yung R, Chang S, Hemati N, Johnson K, Richardson B. Mechanisms of drug-induced lupus. IV. Comparison of procainamide and hydralazine with analogs in vitro and in vivo. Arthritis Rheum. 1997 Aug;40(8): 1436-43.
7 Petri M. Sex hormones and systemic lupus erythematosus. Lupus. 2008 May; 17(5):412-5.

8 Oldstone MBA. Molecular mimicry and immunemediated diseases. FASEB J. 1998 Oct;12(13): 1255-65.

9 Ramos-Casals M, Cuadrado MJ, Alba P, Sanna $G$, Brito-Zerón P, Bertolaccini $L$, et al. Acute viral infections in patients with systemic lupus erythematosus: description of 23 cases and review of the literature. Medicine. 2008 Nov;87(6):31 1-8.

10 Tan EM, Cohen AS, Fries JF, Masi AT, McShane DJ, Rothfield NF, et al. The 1982 revised criteria for classification of systemic lupus erythematosus. Arthritis Rheum. 1982 Nov;25(1 1):1272-7.

11 Petri M, Orbai AM, Alarcón GS, Gordon C, Merrill JT, Fortin PR, et al. Derivation and validation of the Systemic Lupus International Collaborating Clinics classification criteria for systemic lupus erythematosus. Arthritis Rheum. 2012 Aug;64(8):2677-86.

12 Bombardier C, Gladman DD, Urowitz MB, Caron D, Chang $\mathrm{CH}$, Committee on Prognosis Studies in SLE. Derivation of the SLEDAI: a disease activity index for lupus patients. The Committee on Prognosis Studies in SLE. Arthritis Rheum. 1992 Jun;35(6):630-40. 
13 Bangham CRM. The immune response to HTLV-I. Curr Opin Immunol. 2000 Aug;12(4):397-402.

14 Fujinami RS, von Herrath MG, Christen U, Whitton JL. Molecular mimicry, bystander activation, or viral persistence: infections and autoimmune disease. Clin Microbiol Rev. 2006 Jan;19(1): 80-94.

15 Ray S, Sonthalia N, Kundu S, Ganguly S. Autoimmune disorders: an overview of molecular and cellular basis in today's perspective. J Clin Cell Immunol. 2012 Oct;S10:003.

16 International Committee on Taxonomy of Viruses. Virus taxonomy: 2015 release [Internet]. London: ICTV; 2015 [cited 2016 May 5]. Available from: http://www.ictvonline.org/virusTaxonomy.asp.

17 Jesus O, Smith PR, Spender LC, Karstegl CE, Niller $\mathrm{HH}$, Huang D, et al. Updated Epstein-Barr virus (EBV) DNA sequence and analysis of a promoter for the BART (CST, BARFO) RNAs of EBV. J Gen Virol. 2003 Jun;84(Pt 6):1443-50.

18 Longnecker RM, Kieff E, Cohen JI. Epstein-Barr virus. In: Knipe DM, Howley PM, editors. Fields virology. 6th ed. Philadelphia: Lippincott Williams \& Wilkins; 2013. 64 p.

19 Centers for Disease Control and Prevention. Epstein-Barr virus and infectious mononucleosis [Internet]. Atlanta: CDC; 2015 [cited 2016 Apr 6]. Available from: http://www.cdc.gov/epstein-barr/ about-ebv.html.

20 Deng Y, Tsao BP. Genetic susceptibility to systemic lupus erythematosus in the genomic era. Nat Rev Rheumatol. 2010 Dec;6(12):683-92.

21 Poole BD, Scofield RH, Harley JB, James JA. Epstein-Barr virus and molecular mimicry in systemic lupus erythematosus. Autoimmunity. 2006 Feb;39(1):63-70.

22 Gross AJ, Hochberg D, Rand WM, Thorley-Lawson DA. EBV and systemic lupus erythematosus: a new perspective. J Immunol. 2005 Jun;174(11): 6599-607.

23 Harley JB, James JA. Epstein-Barr virus infection induces lupus autoimmunity. Bull NYU Hosp Jt Dis. $2006 ; 64(1-2): 45-50$.

24 Poole BD, Gross T, Maier S, Harley JB, James JA. Lupus-like autoantibody development in rabbits and mice after immunization with EBNA- 1 fragments.J Autoimmun. 2008 Dec;31(4): 362-71.

25 Heegaard ED, Brown KE. Human parvovirus B19. Clin Microbiol Rev. 2002 Jul; 15(3):485-505.

26 Kerr JR, Bracewell J, Laing I, Mattey DL, Bernstein RM, Bruce IN, et al. Chronic fatigue syndrome and arthralgia following parvovirus B19 infection. J Rheumatol. 2002 Mar;29(3):595-602.
27 Kerr JR. The role of parvovirus B19 in the pathogenesis of autoimmunity and autoimmune disease. J Clin Pathol. 2016 Apr;69(4): 279-91.

28 Cohen BJ, Buckley MM. The prevalence of antibody to human parvovirus B19 in England and Wales. J Med Microbiol. 1988 Feb;25(2):151-3.

29 Kelly HA, Siebert D, Hammond R, Leydon J, Kiely P, Maskill W. The age-specific prevalence of human parvovirus immunity in Victoria, Australia compared with other parts of the world. Epidemiol Infect. 2000 Jun; 124(3):449-57.

30 Tsujimura M, Matsushita K, Shiraki $H$, Sato $H$, Okochi K, Maeda Y. Human parvovirus B19 infection in blood donors. Vox Sang. 1995 Oct;69(3):206- 12

31 Kerr JR, Boyd N. Autoantibodies following parvovirus B19 infection. J Infect. 1996 Jan;32(1):41-7.

32 Pavlovic M, Kats A, Cavallo M, Shoenfeld Y. Clinical and molecular evidence for association of SLE with parvovirus B19. Lupus. 2010 Jun;19(7):783-92.

33 Tsai CC, Chiu CC, Hsu JD, Hsu HS, Tzang BS, Hsu TC. Human parvovirus B19 NS1 protein aggravates liver injury in NZB/W Fl mice. PLoS One. 2013 Mar;8(3):e59724.

34 Lunardi C, Tiso M, Borgato L, Nanni L, Millo R, De Sandre G, et al. Chronic parvovirus B19 infection induces the production of anti-virus antibodies with autoantigen binding properties. Eur J Immunol. 1998 Mar;28(3):936-48.

35 Adamson-Small LA, Ignatovich IV, Laemmerhirt MG, Hobbs JA. Persistent parvovirus B19 infection in non-erythroid tissues: possible role in the inflammatory and disease process. Virus Res. 2014 Sep;190:8-16.

36 Chen DY, Chen YM, Tzang BS, Lan JL, Hsu TC. Th17related cytokines in systemic lupus erythematosus patients with dilated cardiomyopathies: a possible linkage to parvovirus B19 infection. PLoS One. 2014 Dec;9(12):e113889.

37 Lunardi C, Tinazzi E, Bason C, Dolcino M, Corrocher R, Puccetti A. Human parvovirus B19 infection and autoimmunity. Autoimmun Rev. 2008 Dec;8(2): $116-20$.

38 Proietti FA, Carneiro-Proietti ABF, Catalan-Soares BC, Murphy EL. Global epidemiology of HTLV-I infection and associated diseases. Oncogene. 2005 Sep;24(39):6058-68.

39 Meyer PWA, Hodkinson B, Ally M, Musenge E, Wadee AA, Fickl $\mathrm{H}$, et al. Circulating cytokine profiles and their relationships with autoantibodies, acute phase reactants, and disease activity in patients with rheumatoid arthritis. Mediators Inflamm. 2010;2010:158514. 
40 Iwakura Y, Tosu M, Yoshida E, Takiguchi M, Sato $K$, Kitajima I, et al. Induction of inflammatory arthropathy resembling rheumatoid arthritis in mice transgenic for HTLV-I. Science. 1991 Aug;253(5023): 1026-8.

41 Green JE, Hinrichs SH, Vogel J, Jay G. Exocrinopathy resembling Siögren's syndrome in HTLV-1 tax transgenic mice. Nature. 1989 Sep;34 1 (6237):72-4.

42 Tamegão-Lopes BP, Rezende PR, Maradei-Pereira LMC, Lemos JAR. Carga proviral do HTLV-1 e HTLV-2: um método simples através da PCR quantitativa em tempo real. Rev Soc Bras Med Trop. 2006 nov-dez;39(6):548-52.

43 Ayres M, Ayres Jr M, Ayres DL, Santos AAS. BioEstat 5.0: aplicações estatísticas nas áreas das ciências biológicas e médicas. Belém: Sociedade Civil Mamirauá; 2007. 364 p.

44 Conde SRSS, Marçal AS, Tavares GF, Souza HCB, Vasconcelos VC. Estudo clínico-epidemiológico de pacientes com lupus eritematoso sistêmico, em uma população da Amazônia Oriental. Rev Para Med. 2009 abr-jun;23(2): 1-5.

45 Duarte $C$, Couto $M$, Ines $L$, Liang $M H$. Epidemiology of systemic lupus erythematosus. In: Lahita RG, Tsokos G, Buyon J, Koike T, editors. Systemic lupus erythematosus. 5th ed. London: Elsevier; 2011 . p. 673-96.

46 Smith-Bouvier DL, Divekar AA, Sasidhar M, Du S, Tiwari-Woodruff SK, King JK, et al. A role for sex chromosome complement in the female bias in autoimmune disease. J Exp Med. 2008 May;205(5):1099-108.

47 Zandman-Goddard G, Solomon M, Rosman Z, Peeva E, Shoenfeld Y. Environment and lupusrelated diseases. Lupus. 2012 Mar;21(3): $241-50$.

48 Sauma MFLC, Nunes NAC, Lopes LFM. Estudo retrospectivo das manifestações clínicas e laboratoriais de 104 pacientes com lúpus eritematoso sistêmico (LES), em Belém, PA, Brasil (1990-1999). Rev Bras Reumatol. 2004 mai-jun;44(3): 192-7.

49 Poole BD, Templeton AK, Guthridge JM, Brown EJ, Harley JB, James JA. Aberrant Epstein-Barr viral infection in systemic lupus erythematosus. Autoimmun Rev. 2009 Feb;8(4):337-42.

50 Draborg AH, Duus K, Houen G. Epstein-Barr virus and systemic lupus erythematosus. Clin Dev Immunol. 2012;2012:370516.

51 Tsokos GC, Magrath IT, Balow JE. Epstein-Barr virus induces normal $B$ cell responses but defective suppressor $T$ cell responses in patients with systemic lupus erythematosus. J Immunol. 1983 Oct;131 (4):1797-801.
52 Kang I, Quan T, Nolasco H, Park SH, Hong MS, Crouch J, et al. Defective control of latent Epstein-Barr virus infection in systemic lupus erythematosus. J Immunol. 2004 Jan;172(2): 1287-94.

53 Frappier L. The Epstein-Barr virus EBNA1 protein. Scientifica. 2012;2012:438204.

54 Klutts JS, Ford BA, Perez NR, Gronowski AM. Evidence-based approach for interpretation of Epstein-Barr virus serological patterns. J Clin Microbiol. 2009 Oct;47(10):3204-10.

55 Coskun O, Sener K, Kilic S, Erdem H, Yaman $H$, Besirbellioglu $A B$, et al. Stress-related EpsteinBarr virus reactivation. Clin Exp Med. 2010 Mar;10(1):15-20.

56 Moon UY, Park SJ, Oh ST, Kim WU, Park SH, Lee $\mathrm{SH}$, et al. Patients with systemic lupus erythematosus have abnormally elevated Epstein-Barr virus load in blood. Arthritis Res Ther. 2004 May;6(4): R295-302.

57 Yu SF, Wu HC, Tsai WC, Yen JH, Chiang W, Yuo $C Y$, et al. Detecting Epstein-Barr virus DNA from peripheral blood mononuclear cells in adult patients with systemic lupus erythematosus in Taiwan. Med Microbiol Immunol. 2005 May; 194(3): $115-20$.

58 Mohamed AE, Hasen AM, Mohammed GFA, Elmaraghy NN. Real-time PCR of cytomegalovirus and Epstein-Barr virus in adult Egyptian patients with systemic lupus erythematosus. Int J Rheum Dis. 2015 May; 18(4): 452-8.

59 Lu JJ, Chen DY, Hsieh CW, Lan JL, Lin FJ, Lin SH. Association of Epstein-Barr virus infection with systemic lupus erythematosus in Taiwan. Lupus. 2007 Mar; 16(3): 168-75.

60 Babcock GJ, Hochberg D, Thorley-Lawson DA. The expression pattern of Epstein-Barr virus latent genes in vivo is dependent upon the differentiation stage of the infected B cell. Immunity. 2000 Oct;13(4):497-506.

61 Moore TL. Parvovirus-associated arthritis. Curr Opin Rheumatol. 2000 Jul;12(4):289-94.

62 Watanabe Y, Inove Y, Takatani T, Arai H, Yasuda T. Self-limited lupus-like presentation of human parvovirus B19 infection in a 1 -year-old girl. Pediatr Int. 2009 Jun;51(3):411-2.

63 El-Saadany HF, Talat MA, Salah HE. Parvovirus B19 viremia in children with systemic lupus erythematosus. Egypt J Pediatr Allergy Immunol. $2011 ; 9(2): 71-6$.

64 Hession MT, Au SC, Gottlieb AB. Parvovirus B19associated systemic lupus erythematosus: clinical mimicry or autoimmune induction? J Rheumatol. 2010 Nov;37(1 1):2430-2. 
65 Chen DY, Chen YM, Lan JL, Tzang BS, Lin CC, Hsu TC. Significant association of past parvovirus B19 infection with cytopenia in both adult-onset Still's disease and systemic lupus erythematosus patients. Clin Chim Acta. 2012 May;413(9-10):855-60.

66 Silva CP, Rêgo J, Barbosa VS, Cruz VA, Silva NA. Frequency of antiparvovirus B19 antibodies in rheumatoid arthritis and systemic lupus erythematosus. Rev Bras Reumatol. 2014 Jan-Feb;54(1):21-6.

67 Freitas RB, Wong D, Boswell F, Miranda MFR, Linhares AC, Shirley J, et al. Prevalence of human parvovirus (B19) and rubellavirus infections in urban and remote rural areas in Northern Brazil. J Med Virol. 1990 Dec;32(4):203-8.

68 Freitas RB, Miranda MFR, Shirley J, Tudor R, Desselberger U, Linhares AC. Parvovirus B19 antibodies in sera of patients with unexplained exanthemata from Belém, Pará, Brazil. Mem Inst Oswaldo Cruz. 1993 Jul-Sep;88(3):497-9.

69 Freitas RB, Monteiro TAF, Silva Filho MG, Linhares AC. Association between human parvovirus B19 and arthropathy in Belém, Pará, North Brazil. Rev Inst Med Trop Sao Paulo. 2002 Jan-Feb;44(1): 17-22.

70 Kozireva SV, Zestkova JV, Mikazane HJ, Kadisa AL, Kakurina NA, Lejnieks $A A$, et al. Incidence and clinical significance of parvovirus B19 infection in patients with rheumatoid arthritis. J Rheumatol. 2008 Jul;35(7):1265-70.

71 Koch WC, Adler SP. Human parvovirus B19 infections in women of childbearing age and within families. Pediatr Infect Dis J. 1989 Feb;8(2):83-7.

72 Lobner E, Traxlmayr MW, Obinger C, Hasenhindl C. Engineered $\operatorname{lgGl}-\mathrm{Fc}$ - one fragment to bind them all. Immunol Rev. 2016 Mar;270(1):113-31.

73 Hall WW, Ishak R, Zhu SW, Novoa P, Eiraku N, Takahashi $\mathrm{H}$, et al. Human $T$ lymphotropic virus type II (HTLV-II): epidemiology, molecular properties, and clinical features of infection. J Acquir Immune Defic Syndr Hum Retrovirol. 1996;13 Suppl 1:S204-14.

74 Taylor GP. The epidemiology of HTLV-I in Europe. J Acquir Immune Defic Syndr Hum Retrovirol. 1996;13 Suppl 1:S8-14.

75 Ribeiro M, Catalan-Soares B, Proietti FA. Aspectos epidemiológicos da infecção por HTLV-1 e HTLV-2. Cad Hemominas. 2010;15:89-106.

76 Lipka K, Tebbe B, Finckh U, Rolfs A. Absence of human T-lymphotropic virus type I in patients with systemic lupus erythematosus. Clin Exp Dermatol. 1996 Jan;21 (1):38-42.

77 Boumpas DT, Popovic M, Mann DL, Balow JE, Tsokos GC. Type $C$ retroviruses of the human $T$ cell leukemia family are not evident in patients with systemic lupus erythematosus. Arthritis Rheum. 1986 Feb;29(2):185-8.
78 Koike T, Kagami M, Takabayashi K, Maruyama $\mathrm{N}$, Tomioka H, Yoshida S. Antibodies to human $\mathrm{T}$ cell leukemia virus are absent in patients with systemic lupus erythematosus. Arthritis Rheum. 1985 May;28(5):481-4.

79 Bailer RT, Lazo A, Harisdangkul V, Ehrlich GD, Gray LS, Whisler RL, et al. Lack of evidence for human $T$ cell lymphotrophic virus type I or II infection in patients with systemic lupus erythematosus or rheumatoid arthritis. I Rheumatol. 1994 Dec;21 (12):2217-24.

80 Murphy Jr EL, Ceulaer KD, Williams W, Clark JW, Saxinger C, Gibbs WN, et al. Lack of relation between human T-lymphotropic virus type I infection and systemic lupus erythematosus in Jamaica, West Indies. J Acquir Immune Defic Syndr. 1988;1(1): 18-22.

81 Shirdel A, Hashemzadeh K, Sahebari M, Rafatpanah $H$, Hatef $M$, Rezaieyazdi $Z$, et al. Is there any association between human lymphotropic virus type I (HTLV-I) infection and systemic lupus erythematosus? An original research and literature review. Iran J Basic Med Sci. 2013 Mar;16(3):252-7.

82 Olsen RG, Tarr MJ, Mathes LE, Whisler R, Du Plessis $D$, Schulz EJ, et al. Serological and virological evidence of human T-lymphotropic virus in systemic lupus erythematosus. Med Microbiol Immunol. 1987; 176(2):53-64.

83 Scott T, Goust J, Strange C, Brillman J. SLE, thrombocytopenia, and HTLV-I. J Rheumatol. 1990 Nov; $17(11): 1565-6$

84 Akimoto M, Matsushita K, Suruga Y, Aoki N, Ozaki A, Uozumi $K$, et al. Clinical manifestations of human $T$ lymphotropic virus type I-infected patients with systemic lupus erythematosus. J Rheumatol. 2007 Sep;34(9):1841-8.

85 Miura T, Tanaka H, Making Y, Okamoto K, lida $T$, Komura $K$, et al. Human $T$ cell leukemia virus type I-associated myelopathy in a patient with systemic lupus erythematosus. Intern Med. 1999 Jun;38(6):512-5.

86 Danao T, Reghetti G, Yen-Lieberman B, Starkey C, Wakasugi K, Mclean-Johnson W. Antibodies to the human $\mathrm{T}$ lymphotropic virus type I in systemic lupus erythematosus. Clin Exp Rheumatol. 1991;9:55.

87 Carvalho MMN, Giozza SP, Santos ALMA, Carvalho EM, Araúio MI. Freqüência de doenças reumáticas em indivíduos infectados pelo HTLV-1. Rev Bras Reumatol. 2006 set-out;46(5):315-22.

88 Levin MC, Lee SM, Kalume F, Morcos Y, Dohan Jr FC, Hasty KA, et al. Autoimmunity due to molecular mimicry as a cause of neurological disease. Nat Med. 2002 May;8(5):509-3. 